\title{
Finding Similarities and Differences: An Implementation of Information-gap Game in Teaching Speaking
}

\author{
G. A. P. Suprianti ${ }^{1}$, Ni Wayan Lestari ${ }^{2}$ \\ ${ }^{1,2}$ English Education Department \\ Universitas Pendidikan Ganesha \\ Singaraja, Indonesia \\ 1'gap.suprianti@undiksha.ac.id, 2wayanlesari68@yahoo.com
}

\begin{abstract}
This study aimed at investigating whether or not there was significant effect of information-gap game technique, specifically finding differences and similarities, on the speaking competency of the tenth graders in a high school in Bali. The present study was an experimental research applying posttestonly control group design. Class $\mathrm{X} 2$ and $\mathrm{X} 3$ were chosen as the samples of this study. Class X3 that consisted of 28 students was assigned as the experimental group and class X2 that consisted of 25 students was assigned as the control group. Speaking test, scoring rubric and lesson plan were used for collecting data in this study. The data were analyzed by using descriptive and inferential analysis. The hypothesis testing showed there was significant effect of information-gap game on the students' speaking competency.
\end{abstract}

\section{Keywords - information-gap game, teaching speaking}

\section{INTRODUCTION}

Speaking is an important competency which is used to communicate with others through speech. It involves communicative performance, grammar, pronunciation, vocabulary, etc. Speaking is the process of expressing ideas, feeling or opinion to others in oral. In relation to expressing ideas, feeling or producing, receiving and processing information [1]. Harmer states that there are three main reasons for getting the students to speak in the classroom, namely (1) speaking activities provide rehearsal opportunities - chances to practice real-life speaking in the safety of classroom, (2) speaking tasks in which students try to use any or all of the language they know, and (3) when they have opportunities to activate the various elements of language that they have stored in their brain, they will be able to use those elements fluently without very much conscious thought [2].

In order to master speaking English, there are many factors that influence the students' competency. Gardner in Shuang states that individuals are motivated both internally and externally. Internal motivation comes from inside of the person or learner. While, external motivation comes from outside of the person or learner. One of the external motivations that influence the students' speaking competency is the class atmosphere that created by the teacher. To create the good atmosphere in the classroom, the teacher should develop the techniques in teaching. Developing techniques to motivate students is very important to every teacher because the more motivated the students are the harder they will work to increase their development of English learning [3]. Teaching and learning process is conducted based on the activity with the several characteristics, such as: 1) interactive and inspiring, 2) enjoyable, challenging and motivate the students to actively participate, 3) contextual and collaborative, 4) giving the chance for students' initiative, creativity, and independency and 5) appropriate with the students aptitude, interest, ability and the development of their physic and psychology [4].

Relating to the teaching and learning situation in the classroom, innovative teaching strategy is one of the way to create the effective and interesting learning and teaching process. One of the ways is using games. Game is a kind of entertaining and challenging activity which allows the learners play as well as interact with other learners [5]. Game has a crucial role in improving students' learning motivation [6]. When a game implemented in the classroom, the teacher could provide a useful and meaningful language context. The learners want to take apart, and in order to do the game, the learners should understand what others are saying and they must speak in order to express their own point of view or gave information [5].

By using games in the classroom, the students learn to speak without realizing that they are learning it. It makes the students not afraid in making mistakes when they speak in the classroom. Shaping a learning task in the form of a game often piques the interest of learners who see it as something different to what they normally do in class [7]. Students will learn better if they experienced progress in learning, and games provided opportunities for students to practice and eliminate their fears [6].

There are many benefits of using games in the classroom. According to Nguyen and Khuat in Taheri, using games provide relax and fun environment for learners. It will motivate them to voluntarily involvement in classroom task. In playing games, the learners give attention on the message not on the language [8]. They acquire language unconsciously, with their whole attention engaged by the activity [9]. Freeman in Taheri states that learners enjoy the games because games provide healthy and constructive competition. He also argued that games have real life communication features because players are required to exchange ideas with each other [8]. A good 
designed game could facilitate learners in improving their speaking ability due to real communication context created in the classroom.

Communication games are defined as a set of games that is designed to help student learning English with joyful activities and it is aimed to get learners talk as fluently and quickly as possible [10]. Communication games are the way to get the students to speak in the classroom. They will enjoy and interested with the class because this games can stimulate students' motivation to learn. Besides increasing the students' interest, games also makes the students learn in fun situation and create the good social interaction among the other students in the classroom. It makes the students easy to talk in the class without being worry and shy. Harmer states that informationgap game is one kind of communication gap games [2].

Information-gap game is game that depends on an information gap. It means that one student has to talk to a partner in order to solve a puzzle, draw a picture, put things in the right order or find the similarities and differences between the pictures [2]. Due to many kinds of information-gap game, the researcher focused on finding similarities and differences between the pictures game. It is because finding similarities and differences game is designed to get students talking in detail about the differences between the pictures [2]. Hence, by using finding similarities and differences game in the classroom the students would be able to speak without thinking too much about the mistakes that they would do and focus on the detail about the pictures.

The power of using information-gap game in teaching English was proved by many studies. One of them is a research conducted by Cahyanto, et al. in SMA Negeri 2 Madiun [11]. Based on the research, it was found that information-gap game was able to give effect to the students' speaking ability. The game also increased the students' interest and participation in learning English.

Based on the situation and phenomenon which were explained previously and the strength of information-gap game which was proved by the result of the previous study, the present study investigated the effect of using information-gap game on speaking competency, especially for the tenth grade students in SMA Negeri 1 Sawan in academic year 2016/2017.

\section{RESEARCH METHOD}

The research took place at SMA Negeri 1 Sawan in Sawan sub-district, Buleleng Regency. The research was conducted from $17^{\text {th }}$ of April 2017 until 13 ${ }^{\text {th }}$ of May 2017 in academic year 2016/2017. This research was conducted in 7 meetings for both of the two groups.

This research was an experimental research which was proposed to figure out whether there is any significant different in students' speaking competency that were treated differently or not. This research used posttest-only control group design. The experimental and the control group equated randomly.

After determining the experimental and the control groups, the experimental group was given treatment, they were taught by using information-gap game and control group was taught by conventional technique (presentation, practice, produce technique). To know the effect of the experimental group that taught by using information-gap game and the control group that taught by using conventional technique, both of them were given posttest. The result of the posttest calculated in order to know the effect of the treatment that was given to the experimental group.

The population of this study was the tenth grade students in SMA Negeri 1 Sawan that consisted of about 203 students, who were divided in 8 classes, namely Class X1, X2, X3, X4, X5, X6, X7 and X8.

Through the cluster random sampling, the classes determined as the samples were X2 and X3, where X3 that consisted of 28 students as the experimental group and $\mathrm{X} 2$ that consisted of 25 students as the control group.

There were two variables on the present study, independent and dependent variable. The independent variable of this study was information-gap game and the dependent variable was students' speaking competency.

There were three instruments that were used in this study, namely 1) speaking test, that was given to the students after the treatment. The test was in the form of speaking test. The test was in the form of performance test where the students should perform based on the instruction in the test, 2) scoring rubric, it was used as a tool in doing assessment. The rubric that was used in this study was analytical scoring rubric. 3) lesson plan, it was used as guidance for the teacher in teaching the lesson for experimental group and control group.

Before treatments, the researcher designed the instrument first. The blueprint of the speaking test was designed. The standard competency based on KTSP curriculum was "expressing meaning in short functional text and simple essay about narrative, descriptive and news item in daily lives context". The basic competency was "expressing meaning in simple monologue text by using various written language accurately, fluently, and acceptably in daily lives context in form of: descriptive text". Then, based on standard competency and basic competency the indicators were using simple present in describing person, identifying characteristics of the people who are described, using positive, comparative and superlative degree and applying positive, comparative and superlative degree to compare characteristics of the people who are described.

In order to check the validity and the reliability of the instruments, the instruments were checked by the experts then they were tried out in SMA Negeri 1 Sawan. To check the validity, Gregory formula was used and to check reliability Hyot formula (inter-rater) was used.

In conducting this study, there were several procedures that were conducted. They were: 1) preparing the instruments, 2) consulting the instruments to the experts, 3) checking the validity and reliability of the instruments, 4) selecting two classes as the sample, 5) deciding the experimental group and the control group, 6) giving treatment to the two samples. The experimental group was treated by using information-gap game, while the control one was taught by using conventional technique, 7) conducting posttest for both of the groups, and 8) analyzing the result of the posttest. 
The result of posttest from both of the group was analyzed by using descriptive analysis (mean, median, mode, standard deviation) and inferential analysis (test of normal distribution, test of homogeneity and hypothesis testing). The data was tested by using SPSS Statistics 17.0.

The statistical hypothesis that was used in this study was null hypothesis $\left(\mathrm{H}_{0}\right)$.

$$
\begin{aligned}
& H_{0}: \mu=\mu_{0} \\
& H_{1}: \mu>\mu_{0}
\end{aligned}
$$

Where:

$\mathrm{H}_{0}: \mu=\mu_{0} \quad$ : there is no significant effect of informationgap game on the speaking competency of the tenth grade students of SMA Negeri 1 Sawan.

$\mathrm{H}_{1}: \mu>\mu_{0}$ : there is significant effect of information-gap game on the speaking competency of the tenth grade students of SMA Negeri 1 Sawan.

\section{FINDING AND DISCUSSION}

Before conducting the treatments, testing normality and homogeneity were conducted in both of the groups. The tests were conducted in order to find out whether the groups were normally distributed and homogeneous or not. The students' last speaking score was tested by using SPSS Statistic 17.0.

To test the normality of the data, Kolmogorov-Smirnov statistic was used. The students last speaking score was used in order to test the normality between class X2 and X3. The result of normality test showed that significance value of Experimental group was .200 and the significance value of Control group was .200. Those results mean that the data obtained in this study normally distributed.

Then, Levene's statistic used to test the homogeneity of the data. Based on the result, the significance value was 0.376 . It means that the variances between groups were homogeneous.

Before conducting the treatments, the instruments that would be used were analyzed in order to know whether the instruments valid and reliable or not.

The instruments were checked by the judges before they were used in order to know whether the content was valid or not. The result of the content validity was 0.75 . It means that the instrument was valid and considered at high level. Then, the instruments were revised. The result of the content validity after doing revision was 1.00 . It means that the content of the instrument was valid and it considered at very high level.

After conducting try out at XI IPA1 and checking the result by using inter-rater HOYT'S Formula, the result of inter-rater reliability was 0.940 . It means that the instrument was reliable and can be used as a research instrument.

After making sure that the instruments were valid and reliable, the treatments were conducted. Then, the posttest was conducted in the same for experimental group and control group. Then, the result of the posttest was analyzed in two phases, descriptive analysis and inferential analysis.
Descriptive analysis was conducted to know the mean, median, mode and standard deviation of the two groups. After conducting descriptive analysis of the two groups, the result can be seen in the Table 1 .

Table 1. The Result of Descriptive Analysis of the Two Groups

\begin{tabular}{l|c|l}
\hline \multicolumn{1}{c|}{ Descriptive analysis } & Experimental & Control \\
\hline Mean & 82.7 & 79.1 \\
Median & 84.0 & 80.0 \\
Mode & 84.0 & 80.0 \\
Standard deviation & 4.8607 & 5.0311 \\
\hline
\end{tabular}

In addition, the distribution analysis of data measured in posttest then presented in form of diagram as follow:

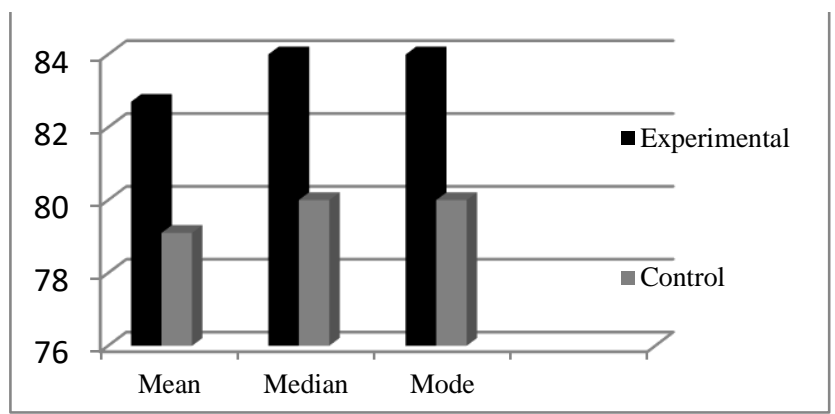

Fig.1. Distribution Analysis of Data Measured in Posttest

Based on the result shown in the Table 1, it can be seen that the mean score of the experimental group was 82.7 , while the mean score of the control group was 79.1. It indicated that the experimental group achieved higher score than control group in the term of speaking competency.

After conducting descriptive analysis, inferential analysis was conducted. This analysis was conducted to find out whether the differences of mean score of the two samples were significant or not. Before conducting hypothesis testing (t-test), the data that would be analyzed should be in normal distribution and the variance should be homogeneous. Hence, normality and homogeneity test were the first two test conducted.

Test of normal distribution was conducted in order to know whether the data obtained was normally distributed or not. Kolmogorov-smirnov statistic was used to find out whether the data were normally distributed or not. Based on the result, the significant value of the experimental group was 0.082 and the control group was 0.56 . The results of the two groups were exceeded 0.05 . Thus, it means that both of samples were normally distributed.

Test of homogeneity had purpose to know whether the data was considered homogenous or not. Levene's statistic was used to test the homogeneity of the data. The result showed that the significant value of the data was 0.864 . It was exceeded 0.05 . It means that the data were homogeneous. 
Then, hypothesis testing was conducted in order to find out whether the differences of mean score of the two samples were significant or not. The hypotheses were:

$\mathrm{H}_{0}: \mu=\mu_{0} \quad$ : there is no significant effect of informationgap game on the speaking competency of the tenth grade students of SMA Negeri 1 Sawan.

$\mathrm{H}_{1}: \mu>\mu_{0}:$ there is significant effect of information-gap game on the speaking competency of the tenth grade students of SMA Negeri 1 Sawan.

The data of the posttest were analyzed by using descriptive and inferential analysis in SPSS 17.0. Based on descriptive analysis, the mean score of the experimental group was 82.7, while the mean score of the control group was 79.1. It means that the experimental group achieved higher score than control group. Furthermore, the result of inferential analysis showed that the value of $t_{\text {observed }}$ was 2.625 . It was higher than the value of the $t_{\text {critical value }} 2.007$. The result indicated that information-gap game gave significant effect on students' speaking competency of the tenth grade students in SMA Negeri 1 Sawan in academic year 2016/2017.

During the treatments, the teacher was guided by lesson plan. The lesson plans were for both experimental group and control group. The lesson plan for experimental group used information-gap game (finding differences and similarities game) as the technique, while lesson plan for control group used PPP as the technique. There were six times treatments, both in experimental group and also in control group. The topics that were taught were describing people and degree of comparison.

The process during the implementation of information-gap game was running well. In the first meeting of the treatments, for experimental group the researcher used information-gap game for the first time. There were several steps in conducting information-gap game in experimental group. The first step was giving knowledge. The teacher gave knowledge about describing people for the students. After the students got knowledge about describing people, the teacher explained about the use of information-gap game to help the students in learning speaking.

The next step was the teacher divided the class into two. Then, the teacher gave the students the pictures of find similarities and differences game. Teacher explained that the students must not look at each other's picture. After that, the students did the activity. Student A started to give information for students B, then students B also gave his/her information for student A. They should find the similarities and the differences between the pictures. After finishing, one or more pairs performed in front of the class to tell about the similarities and differences between the pictures that they got. The steps were the same from the first meeting until the sixth meeting, but the differences were in the topics that were taught.

In the first meeting, the topic was about the clothes. The students learned how to describe people based on the clothes that they wore. In the second, third and fourth meeting, the topic was appearance. The students learned how to describe people based on the characteristics of the appearance. Then, in the fifth and sixth meeting, the topic was degree of comparison.
They learned about the use of positive, comparative and superlative degree and how to compare the people appearances. The treatments were focused on the students' speaking competency. They did not only learned about the theories but also learned about how to speak and how to tell about people description.

In this meeting, the students faced some problems in following the steps of information-gap game. They were difficult to speak spontaneously because they never do that in the previous meeting. They could not speak English well and their pair also could not understand what they said. They looked reluctant to practice the game because this game was new for them and they did not understand the game yet. Relating to the problems, the teacher described the games in detail and then gave example for the students, so they would understand the steps and could play the game well.

The problem also happened in controlling the class. Because they did not understand and could not follow the game, they made noisy and difficult to be controlled. The teacher solved the problem by giving instruction to the students to keep silent. When the students still made noise, the teacher told that she would gave punishment for the students who made noise. Then, they started to follow the activities, even when they did not understand yet about the game.

In the next meeting, the teacher explained more detail about the game before the game was implemented. Some of the students already understood with the game and could follow the game well. They could speak with their pair to find the differences and similarities between the pictures. They used expression that had been tough and practiced to speak spontaneously. But, some other students still confused and could not follow the game. For some students who still had problems, the teacher directly went to the pairs and explain also gave example how to play the game.

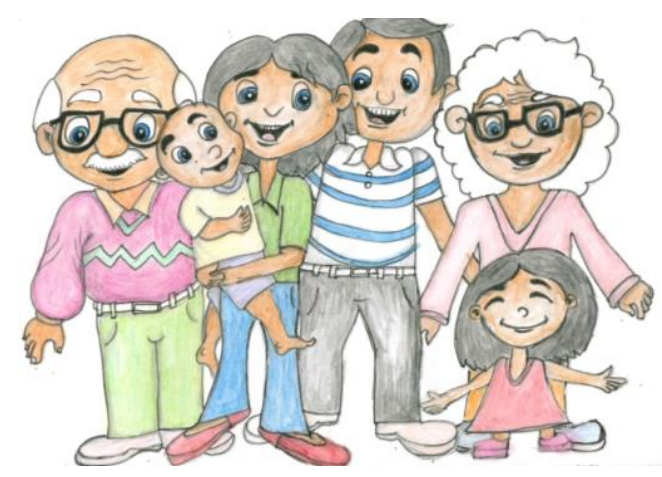

Fig.2. The First Pair of Pictures Used (a) 


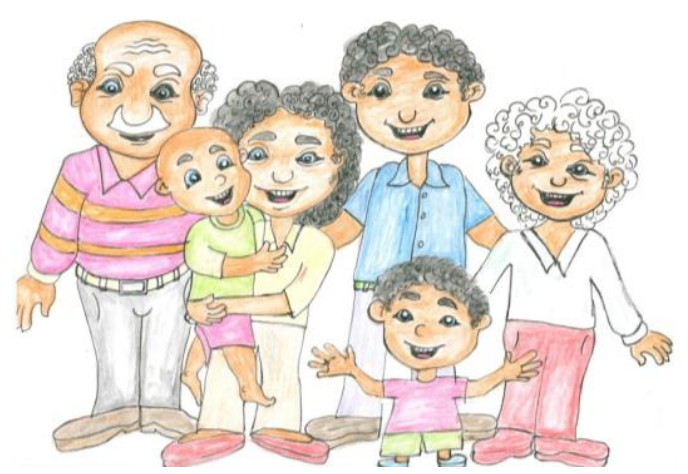

Fig.3. The First Pair of Pictures Used (b)

After implementing information-gap game for six times, the students were already understood about the game. They followed the game well. They also described the pictures well. They looked enthusiast with the lesson. They also enjoyed the class. They spoke spontaneously with their pair. They found similarities and differences between the pictures that they got. During treatments, the researcher used 3 pairs of pictures. The first pair (picture 2 and picture 3) was the pictures about family, there were 6 people in the pictures with different kind of appearances. Picture 1 and picture 2 were similar but they were different. The students described the pictures and find the differences and similarities between picture 2 and picture 3 about the clothes and based on the degree of comparison. This pair was used in first and fifth treatments.
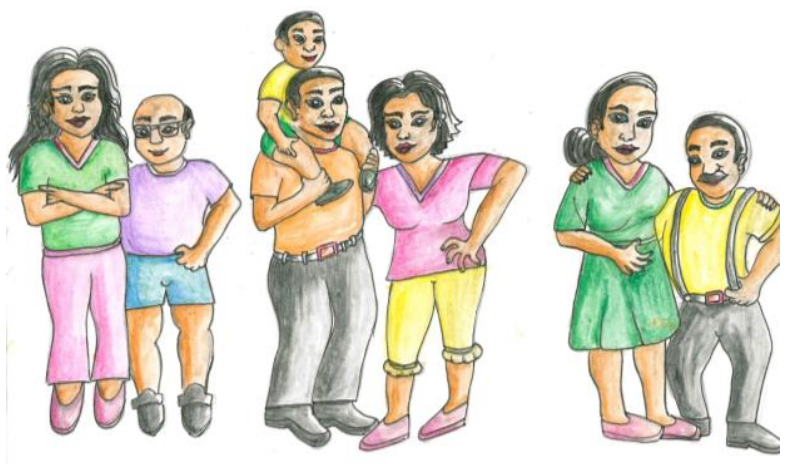

Fig.4. The Second Pair of Pictures Used (a)

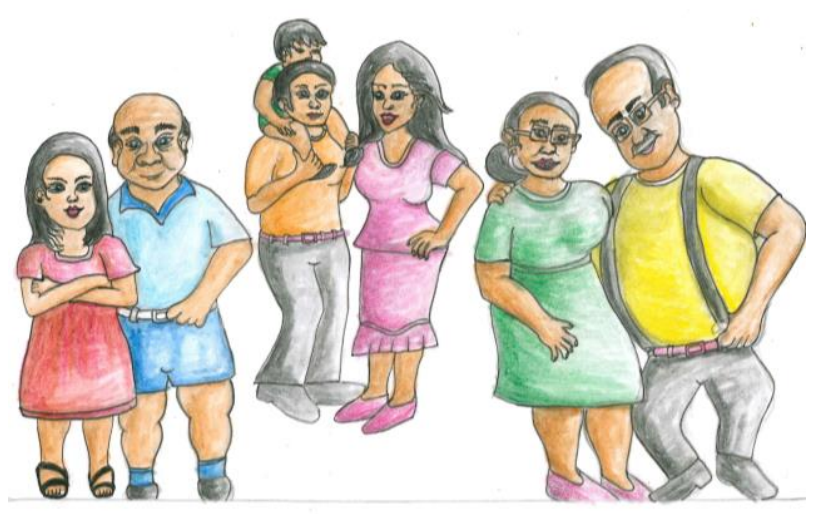

Fig.5. The Second Pair of Pictures Used (b)
The second pair (picture 4 and picture 5) was the picture of a family. There were 7 people in the picture. The students should find the similarities and differences between the picture 4 and picture 5 about the appearance and based on degree of comparison. This pair was used in the second and sixth treatments. The last pair (picture 6 and 7) was also the picture of family which included 4 people. The students should find the similarities and differences between picture 6 and picture 7 based on the appearances.

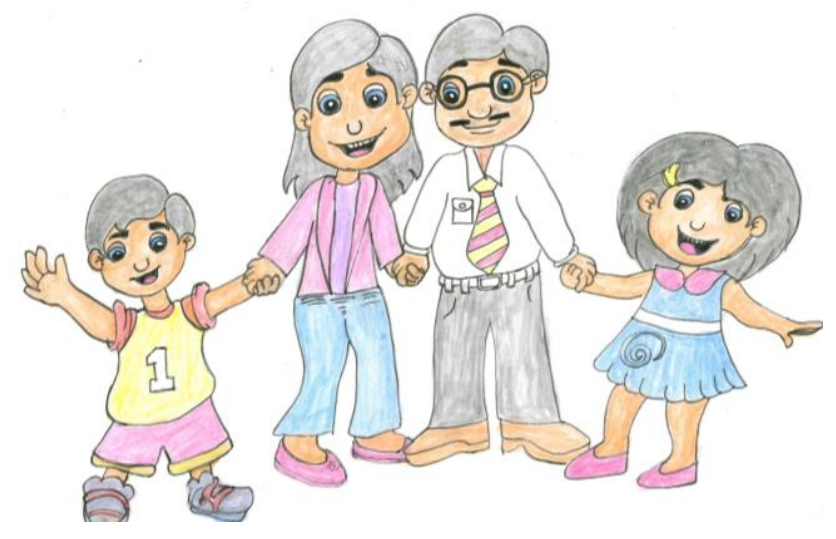

Fig.6. The Third Pair of Pictures Used (a)

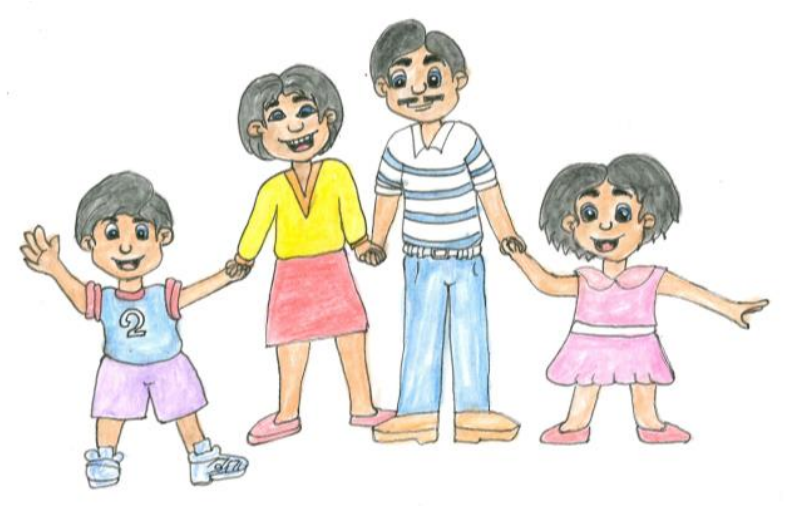

Fig.7. The Third Pair of Pictures Used (b)

Then, after the students already understood and could describe the picture orally, the posttest was conducted. In the posttest, students' pronunciation, content, accuracy, fluency and vocabulary were scored and analyzed. In the process of analyzing the students' pronunciation, content, accuracy, fluency and vocabulary, the students still had some problems. Those problems were related to the students' pronunciation, accuracy, content, fluency and vocabulary.

First, the students had some problems in pronouncing some words. Most of the students did mistakes in pronouncing the words. Both of the groups had problem in pronouncing words. The number of words that were mispronounced was quite similar between the experimental group and control group. The number of words that were mispronounced in experimental group was 35 while the number of words that were mispronounced in control group was 37. But the frequency of error in control group was higher than experimental group. For example in the word "has". In experimental group the 
frequency of error was 12 while in control group the frequency of error was 20. Most of the students in experimental group had problem in pronouncing the word "has", "taller", "old" and "hair". Meanwhile the students in control group had problem in pronouncing the word "has", "higher", "taller" and "old".

Second, the students in experimental group and control group did some errors in accuracy. They had problem in using grammar. There were some grammatical errors that they had done. Based on the analysis of posttest, the number of error in using the suffix 's' in experimental group was 10 and the number of error in using the suffix ' $s$ ' in control group was 11 . Then, the number of error in sentence structure was 6 in experimental group, while in control group the number of error in sentence structure was 28 .

Third, the students' problem was related to content. In experimental group and control group, most of the students already spoke with relevant content. But, there were some students spoke irrelevant content. The test was given by the researcher was describing 2 people and compare them, but some students only describe a person, the other students already described two people but they did not compare them. Most of the students described their parent, brother, sister and also their friends.

Fourth, the students in both group faced any problem in their fluency. Most of the students in experimental and control group spoke at normal speed, not very slow and not very fast. There were some students who spoke very fast because they memorized the text so hard. Meanwhile, there were some students who spoke very slowly with long pause. They seemed so nervous and unconfident.

Lastly, some students' vocabulary needed to be improved. By seeing the result of the posttest, the students in experimental as well as in control group used the appropriate vocabulary. They also used interesting and vivid word choice. But, there were some students who spoke by using monotonous sentence style. For example "my mother has white skin. My father has brown skin. He has black hair. She has long hair."

Then, according to theoretical review which was stated in previously, it was stated that speaking is the process of expressing ideas, feeling or opinion to others in oral. Speaking is an interactive process of constructing meaning that involves producing, receiving and processing information, and the presence of speaker and listener [1]. By implementing information-gap game, the students expressed their ideas, feeling and opinion in oral to their pair. In the process of information-gap game implementation the students produced, received and processed the information that were given by their pair and found similarities and differences between the pictures based on the information that they got.

Hadfield states that a game is an activity with rules, a goal and an element of fun. Games will make a fun and relaxing learning atmosphere [12]. In line with this theory, during implementing information-gap game, there were several rules that should be followed by the students, such as 1) after the teacher gave the pictures for each pair, students A should not show their picture to students B and vice versa, 2) the students should speak to give their information to their pair, 3) the students should find the similarities and differences between the pictures that they and their pair have, 4) the pair that got the most number of similarities and differences was the winner and get reward, in the classroom, the teacher gave additional score as the reward, 5) the pair that got the worst number of similarities and differences got punishment from the teacher and the other students, during the class they got direct punishment, such as singing in front of the class. During the treatments, the students looked so fun and relaxed in following the class activities. They could speak without being worried in making mistakes, because they only spoke with their pair. That situation made the students spoke more than usual and practiced to speak as much as possible. Thus, it could be assumed that between the theory and the implementation of information-gap game were appropriate.

The result obtained in this study was the same as the results of some studies that related. The result of the study which conducted by Jondeya proved that information-gap game gave significant effect on students' speaking ability [13]. This present study was also supported by the research conducted by Nuraeni which found that there was significant difference between students' score in learning speaking by using information-Gap and without using information-Gap. In conclusion, using information-Gap is effective and applicable for teaching speaking at the second grade students of MTs Khazanah Kebajikan Pondok CabeIlir [14]. There were some differences between the present study and the previous studies, such as, the number of sample and the setting of the study. Even there were some differences between the previous and the present study, the result of each study was similar.

The result of each study was information-gap game gave the significant effect on students' speaking competency. Thus, it could be concluded that information-gap game gave the significant effect on students' speaking competency through its possibility in giving most beneficial effect. The beneficial effect that was given by this game such as could make the students speak spontaneously without text, could give the students chance to speak in the classroom without feel worry with the mistakes, could make the class atmosphere more funny and enjoyable also made the students active. Moreover, after implementing information-gap game, the students' comprehension with the material (describing people and degree of comparison) and ability in using vocabulary about the topic that they talked were significantly influenced. It can be seen from the result of the posttest score which showed that the score of content and vocabulary were almost obtained by the students in experimental group were almost high.

\section{CONCLUSION AND SUGGESTIONS}

Based on the t-test, it can be concluded that there was significance effect of information-gap game on speaking competency of the tenth grade students in SMA Negeri 1 Sawan. In relation with the previous discussion, the researcher proposed some suggestions, as follows:

For English teacher, Information-gap game is recommended for teaching speaking. This game could make the students more active in the classroom and practice their speaking during the class. There are some things that should be 
considered by the teacher while using information-gap game in the classroom, such as 1) the teacher should describe in details about how to play the game because the students are difficult to understand the game, 2) the teacher should be able to control the class because when the students play the game, they will make noise and even disturb the other students.

For the other researchers who are interested in teaching English especially speaking, it is suggested to conduct other researches in different level of education, because this game is appropriate with all level of students.

\section{REFERENCES}

[1] H. D. Brown, Principles of Language Learning and Teaching. White Plains, NY: Longman, 2001.

[2] J. Harmer, The Practice of English Language Teaching. Pearson Longman, 2007.

[3] L. Shuang, How to Motivate the Student's Interest in English Learning. Platteville: University of Wisconsin, 2009.

[4] Menteri Pendidikan dan Kebudayaan Republik Indonesia, Peraturan Menteri Pendidikan dan Kebudayaan Republik Indonesia Nomor 103 Tahun 2014 tentang Pembelajaran pada Pendidikan Dasar dan Pendidikan Menengah. Indonesia, 2014, pp. 1-5.

[5] A. Wright, D. Betteridge, and M. Buckby, Games for Language Learning. Cambridge University Press, 2006.

[6] N. W. S. Mahayanti, G. A. P. Suprianti, and I. P. I. Kusuma, "Language Learning Games Development Based on Curriculum
2013," J. Educ. Technol., vol. 1, no. 1, pp. 61-70, 2017.

[7] A. Simpson, Using Games in the Language Classroom. Los Gatos: Adam Simpson at Smashwords, 2015.

[8] M. Taheri, "The Effect of Using Language Games on Vocabulary Retention of Iranian Elementary EFL Learners," J. Lang. Teach. Res., vol. 5, no. 3, pp. 544-549, 2014.

[9] D. Cross and C. V. (Caradog V. James, A Practical Handbook of Language Teaching. Prentice Hall, 1992.

[10] Ulviana, "Improving Students ' Ability through Communication Games," Universitas Islam Negeri Sraif Hidayatullah Jakarta, 2011.

[11] A. W. R. Ferry Sunu Cahyanto, Johannes A. Prayogo, "Using Pictures Information Gap Games to Improve the Speaking Ability of the Tenth Graders of SMAN 2 Madiun," Universitas Malang, 2013.

[12] J. Hadfield, Elementary Vocabulary Games: A Collection of Vocabulary Games and Activities for Elementary Students of English. Longman, 1998.

[13] R. S. Jondeya, "The Effectiveness of Using Information Gap on Developing Speaking Skills for the Eighth Graders in Gaza Governorate Schools," Al-Azhar University-Gaza, 2011.

[14] Nuraeni, "The Effectiveness of Information - gap toward Students' Speaking Skill," Universitas Islam Negeri Sraif Hidayatullah Jakarta, 2014. 